Article

\title{
Social Media Systems in the Workplace: Toward Understanding Employee Knowledge Creation via Microblogging within Shared Knowledge Domains
}

\author{
Simon Cleveland \\ College of Engineering and Computing, Nova Southeastern University, Ft. Lauderdale, FL 33314, USA; \\ sc1674@nova.edu
}

Academic Editor: Remo Pareschi

Received: 22 April 2016; Accepted: 15 July 2016; Published: 18 July 2016

\begin{abstract}
Adoption of social media systems (SMS), proprietary microblogging platforms in particular, for the purposes of information sharing has been increasingly on the rise among corporations. While Twitter is the preferred microblogging tool by the general public, there is scant research to address its viability as a conduit to facilitate knowledge creation among corporate users. As a result, this conceptual paper explores seven crucial Twitter features and derives to seven propositions that demonstrate how microblogging can enable knowledge creation among employees within shared knowledge domain.
\end{abstract}

Keywords: microblogging; social media systems; knowledge creation; pervasiveness; tagging; communication; Twitter

\section{Introduction}

One of the main goals for any organization is to prevent the reoccurrences of the same errors committed by its employees, because such errors are costly. To avoid such recurrences, companies create procedures to capture and store subject matter experts' knowledge [1]. Unfortunately, extant literature demonstrates that such procedures are not as effective as expected, because employees lack motivation, or are resistant to new technology [2,3]. For example, one study showed that while over $60 \%$ of the surveyed companies had created such procedures, nearly $90 \%$ of these companies were not following these procedures [4]. As a result, newly hired staff at these organizations has the potential to repeat the same errors as their veteran coworkers had committed earlier.

While reoccurrences of such errors result in loss of productivity for businesses, the expected drain of experiential knowledge has a greater potential to impact any company once the projected 3.6 million baby boomers exit the work force by 2020 [5]. The outcome of such knowledge loss will have wide negative reverberations across multiple industries. For example, in the technology industry nearly two-thirds of project endeavors already fail as a result of inexperienced staff [6].

Companies employ numerous strategies to combat this knowledge deficit. One of the most common ones is to invest in information and communication technologies (ICT) that facilitate the capture and transfer of knowledge among employees. For example, in 2013 alone, business invested $\$ 330$ billion on the acquisition and integration of these technologies [7].

Among the ICTs, social media systems (SMS), microblogging in particular, are gaining wider acceptance among organizations for the purposes of knowledge exchange [8]. The microblogging platforms allows users to setup personal profiles that list their expertise, interests, and personal photos. Users can also subscribe to follow and read the posts of others, therefore gaining useful knowledge through discussions, idea sharing, and collaboration with their immediate network. Extant literature shows that microblogging can be used to share stories [9], to communicate and reflect [10,11], and to 
support collaboration and knowledge transfer [12]. Furthermore, research suggests that Gen $X$ and Gen Y professionals are highly likely to select SMS for team communication, compared to traditional communication channels [13].

While there is an abundancy of studies on specific factors that impact users' intent to select specific technologies for knowledge exchange [14-16], there is lack of research on how specific features of the SMS, and of microblogging platform in particular, facilitate the knowledge creation processes. As a result, this conceptual paper explores several features of one of the most widely used microblogging platforms, Twitter. It expands the scope and theoretical framework of prior research on microblogging for knowledge sharing [17], microblogging influence on users' attitudes toward knowledge sharing [18], and microblogging effectiveness for capturing quality knowledge [19].

The main research question for this study is: What specific microblogging features can enable knowledge creation practices of corporate microbloggers? Through literature review, the study extracts seven propositions and outlines a model to explain how SMS enhance the corporate knowledge creation process.

The remainder of the paper is structured as follows. First, literature review is performed to examine the phenomenon of corporate knowledge creation. Next, an examination of a specific set of microblogging features is performed and seven propositions are extracted to create a microblogging model for organizational knowledge creation. The paper concludes with recommendations for future research.

\section{Literature Review}

\subsection{Corporate Knowledge Creation: Knowledge Patterns, Types and Domains}

Corporate knowledge creation is an act of exchanging information between employees where one individual leads another through a thought process for the purposes of achieving personal insights [20]. It consists of two or more parties who partake in the act by assuming the roles of knowledge suppliers and knowledge seekers [21-23]. In this paper, knowledge seeking process is defined as the active pursuit of information in order to fulfill precise knowledge needs [24]. The process consists of the following steps (as proposed by Belkin [25]): (1) realization of an existing lack of knowledge on the topic; (2) a mission to solicit needed information; and (3) realization of diminished knowledge need. One theory that explains the seeking behavior is the information foraging theory [26] which suggests that the knowledge hunters (seekers) pursue prey (knowledge) that is easy to acquire (readily available). As a result, knowledge that is easily accessible (e.g., electronically vs. paper archives) will be regarded as more desirable since the time and effort to acquire it will be minimal.

The knowledge contributing process is defined as an approach to obtain information for the purpose of diminishing knowledge disparity among individuals or groups [27]. Research suggests that knowledge contributors evaluate benefits and costs prior to engaging in the process in order to minimize the chance of yielding competitive advantage to others or harming their reputation (should any incorrect knowledge be shared) $[24,28]$.

In this paper, it is argued that in the corporate environment, interactions between seekers and contributors will result in a dynamic knowledge exchange process that encompasses the information capture, organization, transfer, and reuse of corporate experiential knowledge [29]. Moreover, the process will be coupled with consistent dissemination, absorption, and utilization of information among the participants for the purposes of building and integrating the explicit and tacit forms of knowledge into their mental models [30-32].

To explain the knowledge exchange process, the organizational knowledge creation theory is utilized, which suggests that knowledge formation occurs through four distinct patterns. According to Nonaka [33], subject matter experiential knowledge (tacit knowledge) does not lend itself to documentation, since it is rooted in the individual's mind. To demonstrate how knowledge is acquired by an individual, Nonaka and Takeuchi [34] proposed a model that outlined knowledge creation 
through the continuous integration of the four specific patterns of knowledge conversion: socialization, externalization, combination, and internalization.

First, the socialization pattern proposed that individuals learn from the experience of others by continuously interacting and imitating experts. Such acts allow them to convert tacit into tacit knowledge. The researchers suggested that socialization occurs through close monitoring and in some instances the simulation of the expert's behavior. Furthermore, some literature suggests that knowledge sharing via socialization requires synchronous interaction between the knowledge contributor and seeker as well as detailed personal note-taking [35].

Next, the act of transferring tacit into explicit knowledge is known as externalization. This process consisted of sharing of ideas, concepts, images, and documents. Studies show that this knowledge conversion process is best accomplished through the use of metaphors and analogies that help establish shared mental models [36,37]. This is most often accomplished through stories-the conveyance of lessons that can aid decision-making and help individuals to recombine knowledge through reflection [38].

The third pattern is known as combination. Here, individuals engaged in explicit to explicit knowledge creation by leveraging information systems, meetings, and conversations to categorize and join knowledge in the combination pattern. Studies suggest that combination can be accomplished through personal reflection as it empowers individuals to integrate best practices within their mental schemas $[39,40]$.

In the last pattern of conversion called internalization, individuals transferred explicit into tacit knowledge through individual and collective reflection. Extant research suggests that the use of lessons learned assessments (e.g., after-action reviews) can help convert knowledge into competency [41].

The knowledge creation patterns discussed so far transcend diverse work environments and corporate settings, yet their artifacts can vary across different organizations. As a result, examination of not only the process of creating knowledge is required, but also the product of this process and its corresponding dimensions. To accomplish this, the following four knowledge types as proposed by De Jong and Ferguson-Hessler [42] and argued by Cleveland et al. [43] were adopted:

(1) Procedural knowledge-this type of knowledge product consists of rules associated with specific work domain and is expressed via figures, documents, and diagrams;

(2) Situational knowledge-knowledge product of this type encompasses specific scenarios at work that necessitate previously formulated mental models developed through problem solving of various work scenarios. This type of knowledge product is typically acquired through hands-on training;

(3) Conceptual knowledge-product knowledge of this type is associated with archetypal work themes. While some of its explicit properties lend its transfer through pictures and symbols, it requires the knowledge seekers to possess tacit understanding of the work domain;

(4) Strategic knowledge- as with the conceptual type, this knowledge product demands inherent conceptual and abstract understanding of the work domain. Since it is constructed through a series of logical actions, the conversion of this knowledge type necessitates reflection and logical analysis of specific work domain's artifacts.

Based on the proposed knowledge patterns and knowledge types, it is argued that information and communication technologies (ICTs) infrastructure can facilitate knowledge creation and transfer among knowledge contributors and knowledge seekers. For example, in a study of 297 small-medium sized enterprises that adopted ICTs, the researchers found positive relationships between ICTs communicative orientation and the four knowledge creation patterns [44]. Similarly, electronic repositories have been found to be useful tools for facilitating knowledge creation practices and storing knowledge products $[45,46]$. In a study among 315 employees at a single organization, the results showed that intention to use social media for knowledge seeking and contributing is determined by employees' perceived usefulness of social media [15]. In the same study, researchers 
demonstrated that individuals with greater experience in using social media had the strongest knowledge contribution intentions.

One SMS type, known as microblogging, has recently emerged as an effective ICT for capturing and disseminating usage practices [47]. This SMS allows users the ability to share short messages via a variety of devices connected to the Internet [48]. The most popular microblogging platform is Twitter, which has over 300 million active users [49]. Twitter limits users' posts to a mere 140 characters in length, yet research shows that the limit is adequate for the creation of meaningful, reflective posts that foster user interaction to sustain a knowledge sharing culture [50]. Moreover, a number of studies report that microblogging interaction leads to deeper cognitive engagement through dialogue that supports transfer of learning between formal and informal learning contexts [51,52].

To demonstrate knowledge creation via microblogging, the study of Alavi and Leidner [53] is used, who argued that knowledge has the properties of both an object (can be acquired, processed, and codified) and a process (for sharing expertise). In each of these properties, the microblogging platform can facilitate knowledge creation. The following two examples are proposed to illustrate the argument.

\subsubsection{Knowledge Creation within the Shared Knowledge Domain}

First, a scenario is examined where knowledge acts as an object and process within the user's domain of experience. In this example, an experienced technology project manager A (TPM-A) can use microblogging to create various knowledge types (e.g., procedural and situational) and knowledge objects (e.g., notes, lessons, and stories about a specific project). When other TPMs, familiar with the same technology domain, access the posts made by TPM-A, they can easily convert the knowledge from the knowledge objects as a result of the mental model and experiential understanding they have within the domain. If they did not possess understanding of the domain, TPM-A's knowledge objects would make little sense to them due to the 140-character limit. Moreover, other readers of TPM-A's posts, who have knowledge of the domain, may engage TPM-A in a microblogging conversation to clarify and further update their knowledge gaps. In these instances, TPM-A can point the readers to other websites with additional knowledge content, by simply posting a web link in his/her posts. As a result, it is argued that microblogging can facilitate knowledge creation through the development of new content, replacement of existing content through the reflection, or socialization practices.

The microblogging platform can serve as the tool to enhance collaboration, communication, teamwork, and understanding between individuals working within the same domain and be used for storage and retrieval of organizational knowledge (in the form of objects such as notes, quick lessons, metaphors, and short stories). Therefore, in the cases where the writer and reader share understanding of a common domain, microblogging can be used for gathering, storing, and transferring knowledge (as an object), as well as a tool for linking knowledge sources (when knowledge acts as a process) [19].

\subsubsection{Knowledge Creation Outside of a Shared Knowledge Domain}

In a contrasting scenario, there exists a situation where knowledge acts as an object and process outside of the user's domain of experience. Here, when users lacks domain understanding (e.g., specific business unit functions), TPM-A's knowledge creation process through the microblogging platform would be severely limited since his/her readers would lack mental models through which to filter the new information and to make sense of it. In such cases, microblogging can only be used as a process for contacting specific sources of knowledge who can help the readers build new mental models through alternate means.

For the purpose of addressing our posted research question, in this paper the focus is only on the first scenario by demonstrating how specific microblogging features help facilitate the organizational knowledge creation processes within a shared knowledge domain.

Figure 1 illustrates the plan to integrate the four distinct patterns of knowledge creation with the specific microblogging features. The significance of the concentric circles and arrows between the 
various knowledge patterns suggest that knowledge conversion can occur simultaneously among any and all identified patterns without specific direction. The microblogging features are located at the center of the process as factors that enhance the knowledge creation patterns.

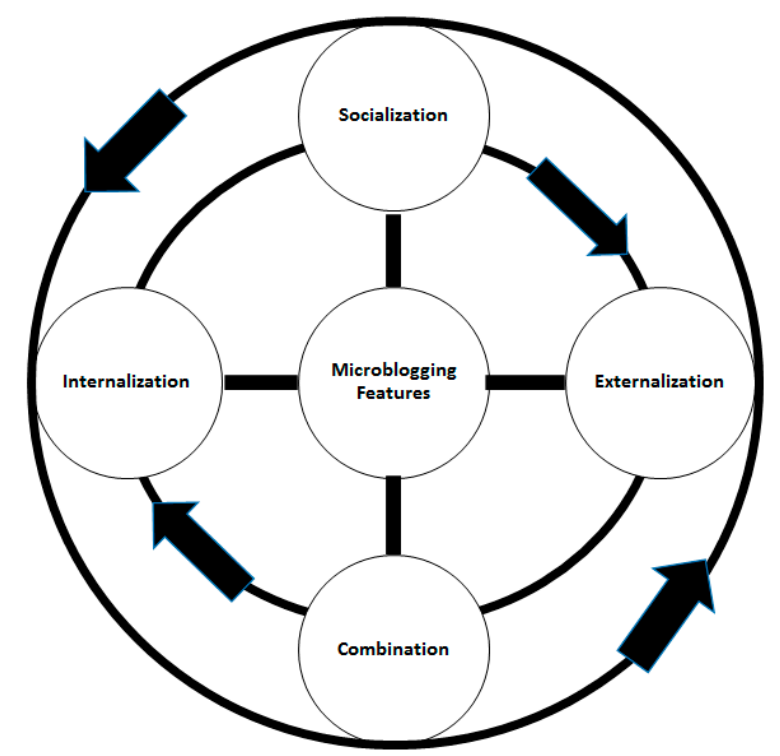

Figure 1. Integration of knowledge creation patterns with SMS microblogging features within shared knowledge domain.

\subsection{Microblogging Features}

Microblogging platforms contain diverse features. The most common free platform is Twitter. In the section below, seven key features of the Twitter platform are addressed and seven corresponding propositions are extrapolated to explain the knowledge creation process through this SMS.

\subsubsection{Pervasiveness}

The microblogging platform lends itself to access from any location or device that is connected to the Internet [54]. As a result, the first feature to be examined is its pervasiveness. Providing Twitter users with such an unrestrained access allows them to interact with others by rapidly sharing knowledge for the purposes of fulfilling specific information needs [54-56]. Extant literature shows that such needs typically emerge as a result of lack of understanding about how to handle ambiguous problems and a need of knowledge on potential courses of action [26].

To explain the knowledge seeking practices, the information foraging theory is used, which anthropomorphizes value-added knowledge as prey that is often hidden in the environment (e.g., online documentation, books, or people) [26]. The hunters (i.e., knowledge seekers), who attempt to locate information from such environment, will have to expend certain energy and time to find the needed knowledge. Like predators, who track only a chosen prey, these information foragers will be forced to decide whether specific hard-to-locate data will maximize their overall gain of information in relationship to their particular knowledge needs [26]. It is argued that any system that minimizes the seekers' effort and time to locate data, while maximizing the achievement of value-added knowledge, will be their preferred initial conduit. The higher pervasiveness of the microblogging SMS will allow seekers to locate knowledge sources or knowledge objects without the need to expand greater energy than the one needed to search for specific books or to comb through online documents. As a result, seekers may default to microblogging as an initial knowledge medium.

As a result, the first proposition states:

P1. Microblogging pervasiveness will have a positive impact on users' knowledge seeking process. 


\subsubsection{Brevity}

Communication and collaboration platforms, such as email or message boards, do not restrain the textual quantity of users' messages. In contrast, the Twitter platform limits user posts to 140 characters. While this limit shortens the narratives, it promotes broadening of the posted content as a result of numerous contributions by different users. As a result of this brevity, knowledge content is not only broadened, but also created with decreased individual effort and increased frequency. Moreover, the knowledge creation process is performed as a collaborative effort by a broader-based community [54,57].

Extant studies reveal that the greater the perceived ease of use of a system, the higher the user's attitude toward the use of such systems [58]. For example, Hsu and Lin [59] found that the user's attitude toward using online blogging was impacted by ease of use of such systems. Furthermore, Wright [10] performed a study on the use of microblogging among eight graduates who posted microblogs three times each workday regarding their daily experiences with solving problems. A total of 494 participant postings were made via Twitter over the seven-week period with a mean of 60 tweets per participant. The results showed that the 140-character posting limit helped the users focus their thinking to reflect purposefully on their experiences. The posts captured the participants' reflective thinking in a chronological order, while at the same time reduced isolation and fostered a sense of community.

Furthermore, studies have shown that microblogging can be used to group posts into meaningful stories. This phenomenon is referred to as social curation, where specific sites (e.g., Storify and Togetter) are used to group multiple posts into a story. For example, in one particular study, a total of 10.2 million microblogging posts from 800,000 users were analyzed [9]. The researchers found that the posts could be grouped into 96,000 lists with a stories consisting of diaries (9\%), problem solving (16\%), collections of long articles (19\%), and conversations on specific topic (19\%). Such wealth of communication between users suggests that the 140 character limit can actually serve as a conduit to enhance storytelling for the purposes of knowledge sharing.

As a result, it is proposed that:

P2. Microblogging brevity will have a positive impact on users' knowledge contributing process.

\subsubsection{Knowledge Source Profile}

The Twitter platform provides users with the ability to setup individual profiles. A profile consists of a picture of the user, short biography, source location, a web link to site with additional information, and a stream of the user's post in a time sequence. As a result, knowledge seekers can develop a perception of a source's credibility and expertise from within a shared knowledge domain by studying the source's profile (including the examination of the source's posted content) $[19,60]$. Since the knowledge provider's Twitter posts are listed in a time-based sequence, knowledge seekers can piece together a story simply by scrolling through the timeline and reading the posts of the knowledge provider.

Studies have shown that knowledge source credibility has an impact on knowledge sharing practices in organizations. For example, researchers have found that greater credibility leads to higher knowledge transfer among the knowledge source and knowledge recipients [61,62]. Moreover, credibility of microblogging knowledge sources has also been studied. For example, Morris, Counts, Roseway, Hoff and Schwarz [60] conducted a survey of 256 Twitter users and discovered that several factors contributed to the users' perceptions of low credibility of specific knowledge sources. The study found that users' perceptions of a knowledge source credibility decreased if he or she used non-standard grammar, default account image (or avatar), and following a large number of other users. In contrast, the credibility of sources increased if they had author influence (measured by number of followers, number of retweets, i.e., reposting of the author's original posts), large number of mention counts, and topical expertise (determined by the source's Twitter homepage) and reputation. 
Such studies suggest that the profile and historical posting features of the microblogging platform provide users with the ability to develop trust in the knowledge credibility of knowledge sources. As a result, it is proposed that:

P3. Microblogging knowledge source profile will have a positive impact on users' knowledge seeking process.

\subsubsection{Subscription}

Studies demonstrate that trust is an essential ingredient in the motivation process to share knowledge among sources and recipients [63]. For example, a microblogging study of 11 users at an IT company showed that the readers perceived the knowledge shared by the expert they purposefully chose to follow as trustworthy [64]. Furthermore, literature shows that the enthusiasm to seek knowledge is greater among knowledge seekers if the knowledge contributors are perceived as trusted leaders since the seekers frequently feel a higher sense of relatedness, mutual cohesion, and commitment to a common cause with such leaders $[65,66]$. These leaders are regarded as trusted experts who provide valuable and timely knowledge. In another study among the top eight microblogging users of a homegrown microblogging platform at a Fortune 500 company, the researchers demonstrated that knowledge seekers were able to obtain needed information by easily following up with experts [67]. Knowledge seekers were able to acquire best-practices with regards to specific business challenges, and remain up-to-date on the latest procedures, standards, quality, and documentation processes.

The results also showed that perceived benefits consisted of locating the required information, accessing expert knowledge, and enhancing learning from the network. Moreover, knowledge seekers reported additional organizational benefits such as improved flow of information, worldwide networking, promotion of knowledge management practices and learning, and diffusion of rich experiences leading to more innovative thinking and better products.

Other studies report that the microblogging platform provided users with the ability to share knowledge without formality or concern for its value, since the publishing and subscribing principle allowed the entire user network to define whether posted content is meaningful, by reposting (or retweeting) such information $[57,68]$. Moreover, users were shown to leverage the knowledge sources' backgrounds and expertise as starting points for a conversation, and to quickly locate knowledge sources with higher quality information than other forms of communication [69]. The subscription feature of Twitter acts as a facilitator for the formation of effective knowledge exchange networks within shared domains.

As a result, it is proposed that:

P4. Microblogging subscription will have a positive impact on users' knowledge seeking and knowledge contributing processes.

\subsubsection{Reposting (RT)}

Alavi and Leidner [53] argued that knowledge creation in individuals occurs as a cognitive process. The preexistence of a common knowledge base can lead to similar conclusions among individuals when new stimuli are introduced. Therefore, when the quality of shared knowledge is poor, it can be expected that decision making outcomes will be also be limited.

Several studies support this argument. For example, Kyoon Yoo et al. [70] showed a link between knowledge quality and innovation. The researchers survey 208 project teams and found that knowledge quality contained three dimensions: contextual relevance (e.g., value-adding and appropriate), accuracy (e.g., timely and reliable), and actionability (e.g., adaptable and easily applied). The results of their study demonstrated that high level of knowledge quality leads to high level of innovation in teams. In another study, Kankanhalli et al. [71] found a relationship between knowledge reuse and knowledge quality. Their study demonstrated that knowledge reuse from electronic 
repositories, as a result of higher knowledge quality, reduced employee response time to customer requests, reduced time required for new employee training, and improved overall customer service.

Twitter allows its users the ability to reuse the information content of others by reposting (retweeting) it with their network. This is accomplished via the RT feature. Knowledge reuse has been investigated in several microblogging studies who aimed to determine what users considered quality microblogging posts. For example, André et al. [72] collected ratings of 43,738 microblog posts from 1443 users. The results indicated that the microblogging posts considered the highest 'worth reading' (e.g., perceived knowledge quality) included questions to followers and specific information sharing.

In another study, Ha and Ahn [73] collected data from 84 Twitter users to determine factors that affect individuals' information processing and sharing behaviors. The results showed that the higher the user's perception of a post's argument quality, the higher the perceived information usefulness of such a post. Moreover, the higher the user's perception of the received post's information usefulness, the higher the intention to share (repost) this post with others.

Finally, Wukich and Mergel [74] performed an analysis of 8671 tweets among government agencies and found that nearly $35 \%$ of the posts were retweets for the purposes of informing and educating the public. The researchers concluded that these agencies reused information since they considered the sources of the data reliable and useful.

Such studies demonstrate that information usefulness is related to both information sharing and argument quality of microblogging posts, which also supports the idea that higher knowledge quality microblogs are reposted by users because they found the knowledge to be useful.

As a result, it is proposed that:

P5. Microblogging reposting will have a positive impact on users' knowledge seeking processes.

\subsubsection{Directed Communication (@)}

Research suggests that microblogging enables directed one-to-one and one-to-many communication processes through both synchronous and asynchronous interaction between users. This occurs as a result of the feedback and subsequent meaningful inquiries that users exchange with one another leading to stimulating social interaction [75]. In Twitter, directed communication is accomplished when a user directs a question or a statement to another user via the use of the @ (at) sign followed by the user ID of the intended user.

Extant literature on directed communication via microblogging shows that over a third of microblogging posts constituted 'small talk' on various topics between users [52]. In this study, conducted among 34 students (21 full-time and 13 part-time) at a large Austrian university, the researchers collected 11,214 microblogging posts. They classified $60 \%$ of these as reply posts, which suggested the existence of directed communication process between the microblogging users. A quarter of all posts were related to the learning while $36 \%$ were categorized as private (small talk). Such social interactions allow users to engage others in strong communities to resolve specific problems. The researchers concluded that microblogging allowed users to achieve information learning through communication, obtain useful recommendations for reflection, and collaborate with others ubiquitously.

Microblogging has also been shown to facilitate knowledge sharing via directed communication in the corporate realm as well. For example, Zhang, Qu, Cody and Wu [11] conducted a five-month study of microblogging users at a Fortune 500 company. The researchers found that microblogging was used to exchange diverse knowledge among numerous users who engaged in directed long conversations. The researchers found that microblogging helped the users to determine the type of work others engaged in, to establish connections, locate answers to specific questions, and improve informal communication. Moreover, the researchers collected 160 responses from subsequent surveys and interviewed 18 users with different participation patterns. They discovered that people considered the microblogging platform to be a more effective way than email or instant messages to locate responses from people whom they did not know (weak-ties). 
Furthermore, in another study at a large IT company, Zhao, Rosson, Matthews and Moran [54] found that over $90 \%$ of user posts were work-relevant. Of these, nearly half were related to tasks statuses, while a quarter of them directly shared information, ideas, and work questions with others. The researchers concluded that microblogging fulfilled a specific communication need for sharing less critical yet specific updates relevant to users' daily work activities. The users were found to form easy-to-understand audiences that helped them determine what knowledge was required. Moreover, the participants of the study reported that microblogging facilitated timely directed communication, and posts with meaningful knowledge context that enhanced social awareness. These studies have led others to conclude that microblogging conversations can also be used for the purpose of sharing lessons with others, thus exchanging new knowledge with new knowledge seekers [76].

Extant literature suggests that directed enterprise microblogging interactions focus on work-related problem solving. For example, Riemer et al. [77] studied 1190 directed microblogging interactions among enterprise users of a microblogging platform. Their results demonstrated that a fifth of these interactions were related to task coordination. These included work progress updates, information seeking on specific tasks, and delegation of work among users. Moreover, $35 \%$ of the interactions were related to coordination of meetings, sharing opinions, and feedback on ideas. In another study, Riemer and Richter [78] analyzed the microblogging interactions of software developers at a private company. They analyzed 648 posts and found that over $60 \%$ of the posts were related to direct problem-solving genres and task coordination. The interactions between the employees were mostly centered on discussion context that help the participants gain a better understanding of the tasks of others.

According to Hauptmann and Gerlach [68], microblogging is a many-to-many communication medium that can improve knowledge exchange and location of subject matter expertise. This suggests that the platform can decrease efforts associated with creating and coordinating a learning network. For example, Meyer and Dibbern [57] found that as with instant messaging, employees used Twitter for directed and informal communication in order to discover work-related information. Moreover, Ehrlich and Shami [69], who studied the microblogging posts of 34 IBM employees, discovered that the posts helped distributed employees feel connected to the rest of the company and keep them informed about work-related developments.

Microblogging directed communication helps employees maintain social awareness and knowledge exchange with wide audiences [8,54,64], fortify their social connections [77], organize ad-hoc team meetings, or meeting one-on-one for discussing an urgent issue [57].

The cited studies suggest that microblogging users utilize the platform to create social connections and develop "swift-tie" trust relationships with others through informal directed communication practices. As a result, it is hypothesized that:

P6. Microblogging directed communication will have a positive impact on users' knowledge seeking and knowledge contributing processes.

\subsubsection{Tagging (Topical Categorization via Hashtags \#)}

Twitter allows users to organize their content by tagging it with specific keywords for the purposes of easy retrieval by others. The tagging feature acts as an indexing by appending a hashtag (denoted by the \# symbol) followed by a specific keyword. Twitter users can add specific hashtag keywords to associate and group the content of their posts with specific topics.

Some researchers have argued that tagging increases users' chances to discover and retrieve new knowledge via the use of tagging [79]. With 500 million Twitter posts daily [80], it is unlikely that a user can discover posts that contain needed knowledge within a shared domain without proper content categorization. Topical categorization of posts becomes more essential since studies show that only $40 \%$ of all tweets are original (the remainder are repeated by the general Twitter population). Of these original posts, only a fifth contain hashtags [81]. Furthermore, nearly $90 \%$ of all hashtags are 
used in fewer than five tweets, while the most popular hashtags were used in only $8 \%$ of all messages containing hashtags.

Such disparities suggest that only a few of the hashtags are considered popular, while there are plenty of new hashtags used consistently. As a result, it is argued that knowledge exchange via microblogging depends on the use of proper content tagging to streamline the discovery and retrieval processes.

Therefore, it is proposed that:

P7. Microblogging topical categorization will have a positive impact on users' knowledge seeking and knowledge contributing processes.

Based on the discussed propositions, the following model is developed to explain the microblogging corporate knowledge creation (Figure 2).

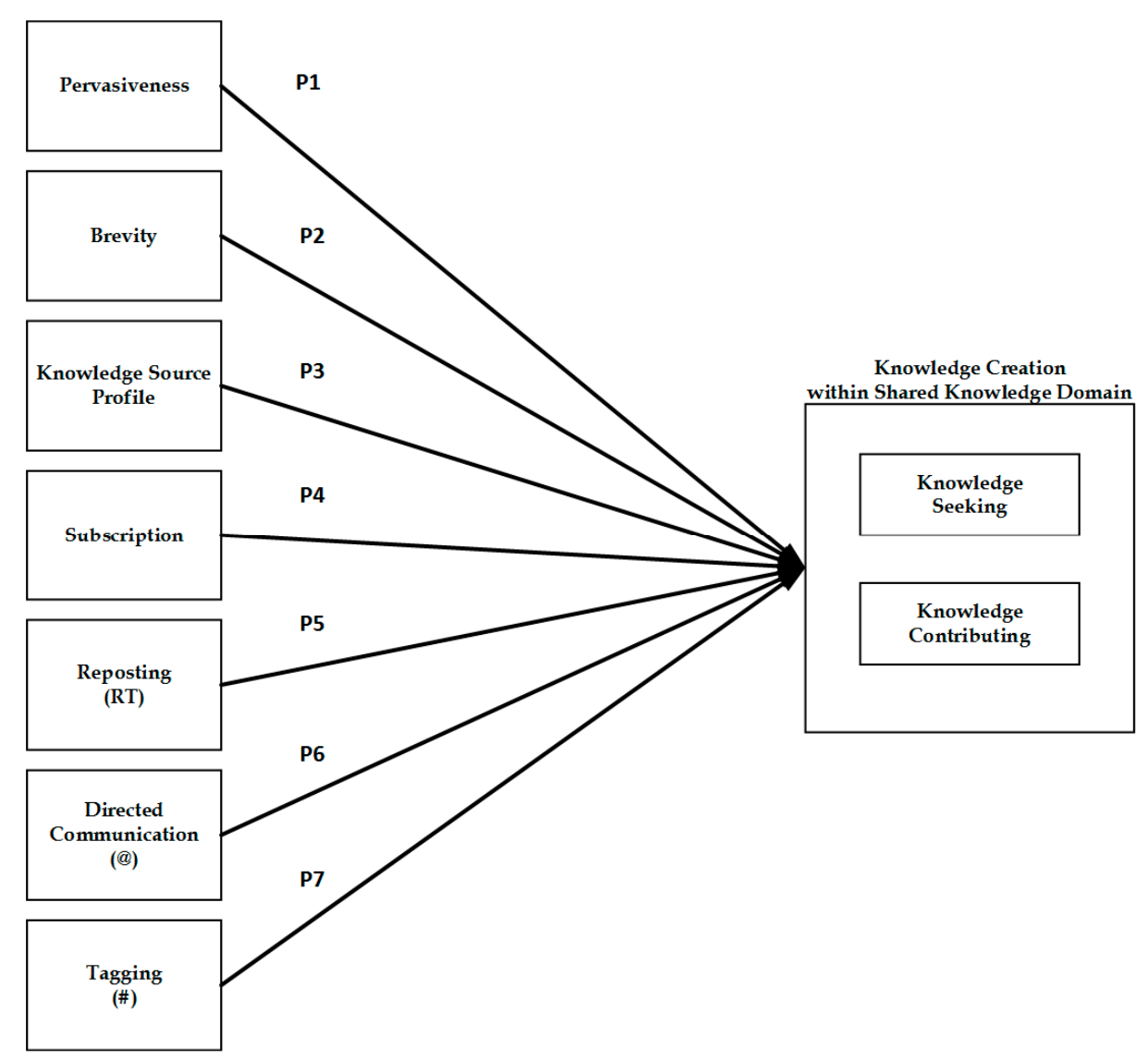

Figure 2. Proposed model for microblogging corporate knowledge creation within shared knowledge domain.

\section{Conclusions}

The goal of this study was to gain an understanding of the microblogging features that can enhance the corporate knowledge creation process via microblogging platforms. The article answered the following research question: What specific microblogging features can enable knowledge creation practices of corporate microbloggers? Seven features of the microblogging platform Twitter were analyzed, and seven propositions where extracted. Finally, a model, consisting of the identified features, was developed to explain how such features impact microblogging knowledge creation within shared knowledge domain in organizations.

The present research has several practical implications. First, the study added value to corporations who already invest nearly $\$ 330$ billion on ICTs to prevent loss of knowledge [7]. This was 
accomplished by focusing on specific features of the SMS, microblogging in particular, which could enhance employees' knowledge seeking and knowledge contributing behaviors. For example, studies suggest that employees spend $61 \%$ of their work week using ICTs to share knowledge, communicate and collaborate with other coworkers [82]. Of these, nearly a third is dedicated to reading and answering e-mails, while nearly a fifth on searching and gathering information, and $14 \%$ of it on communicating and collaborating. While email is still the predominant communication form with 929 million business email boxes worldwide in 2013 [83], the present study suggests that microblogging can facilitate knowledge exchange among employees through its unique features.

Future research will focus on the development of instruments to measure the discussed features. Such studies will validate the model by conducting a quantitative study using survey for the data collection and structured equation modeling for the data analysis. Furthermore, future studies will aim to investigate whether specific groupings of ICTs (e.g., microblogging and online forums) may enhance knowledge sharing behaviors of employees. Such studies will contribute to the collective understanding on what behavioral patterns are influenced by specific system features in order to streamline knowledge exchange among users. Finally, since Twitter may augment its current platform, or new microblogging platforms with alternative features may be introduced to the market, the conceptualization of the model presented in this study may be challenged. Future research should focus on how any new microblogging features may influence corporate knowledge creation processes.

Conflicts of Interest: The author declares no conflicts of interest.

\section{References}

1. Hanisch, B.; Lindner, F.; Mueller, A.; Wald, A. Knowledge management in project environments. J. Knowl. Manag. 2009, 13, 148-160. [CrossRef]

2. Matschke, C.; Moskaliuk, J.; Bokhorst, F.; Schümmer, T.; Cress, U. Motivational factors of information exchange in social information spaces. Comput. Hum. Behav. 2014, 36, 549-558. [CrossRef]

3. Pirkkalainen, H.; Pawlowski, J.M. Global social knowledge management-Understanding barriers for global workers utilizing social software. Comput. Hum. Behav. 2014, 30, 637-647. [CrossRef]

4. Williams, T. How do organizations learn lessons from projects-And do they? IEEE Trans. Eng. Manag. 2008, 55, 248-266. [CrossRef]

5. Toossi, M. Labor force projections to 2020: A more slowly growing workforce. Mon. Labor Rev. 2012, 135, 43-64.

6. Standish Group. Extreme Chaos; The Standish Group International, Inc.: West Yarmouth, MA, USA, 2011.

7. U.S. Census. Information and Communication Technology Survey; United States Census Bureau: Washington, DC, USA, 2013.

8. Seebach, C. Searching for answers-Knowledge exchange through social media in organizations. In Proceedings of the 45th Hawaii International Conference on System Science (HICSS), Maui, HA, USA, 4-7 January 2012; pp. 3908-3917.

9. Duh, K.; Hirao, T.; Kimura, A.; Ishiguro, K.; Iwata, T.; Yeung, C.-M.A. Creating stories: Social curation of twitter messages. In Proceedings of The Sixth International AAAI Conference on Weblogs and Social Media, Dublin, Ireland, 4-7 June 2012.

10. Wright, N. Twittering in teacher education: Reflecting on practicum experiences. Open Learn. 2010, 25, 259-265. [CrossRef]

11. Zhang, J.; Qu, Y.; Cody, J.; Wu, Y. A case study of micro-blogging in the enterprise: use, value, and related issues. In Proceedings of the 28th International Conference on Human Factors in Computing Systems, Atlanta, GA, USA, 10-15 April 2010; pp. 123-132.

12. Menkhoff, T.; Chay, Y.W.; Bengtsson, M.L.; Woodard, C.J.; Gan, B. Incorporating microblogging ("tweeting") in higher education: Lessons learnt in a knowledge management course. Comp. Hum. Behav. 2015, 51, 1295-1302. [CrossRef]

13. Cardon, P.W.; Marshall, B. The hype and reality of social media use for work collaboration and team communication. Int. J. Bus. Commun. 2015, 52, 273-293. [CrossRef] 
14. Chin, C.P.-Y.; Evans, N.; Choo, K.-K.R.; Tan, F.B. What influences employees to use enterprise social networks? A socio-technical Perspective. In Proceedings of the Pacific Asia Conference on Information Systems (PACIS), Singapore, 5-9 July 2015; p. 54.

15. Behringer, N.; Sassenberg, K. Introducing social media for knowledge management: Determinants of employees' intentions to adopt new tools. Comp. Hum. Behav. 2015, 48, 290-296. [CrossRef]

16. El Ouirdi, A.; El Ouirdi, M.; Segers, J.; Henderickx, E. Employees' use of social media technologies: A methodological and thematic review. Behav. Inform. Technol. 2015, 34, 454-464. [CrossRef]

17. Cleveland, S.; Ellis, T. Microblogging for knowledge sharing: An exploratory study. In Proceedings of the 21st Americas Conference on Information Systems, Puerto Rico, 13-15 August 2015.

18. Cleveland, S.; Ellis, T.J. Five capacities that impact attitudes toward knowledge sharing via SNS. In Proceedings of the IEEE SoutheastCon, Fort Lauderdale, FL, USA, 9-12 April 2015.

19. Cleveland, S.; Ellis, T.J. Determining microblogging effectiveness for capturing quality knowledge. In Proceedings of the 19th Americas Conference on Information Systems (AMCIS), Chicago, IL, USA, 15-17 August 2013.

20. McDermott, R. Why information technology inspired but cannot deliver knowledge management. Calif. Manag. Rev. 1999, 41, 103-117. [CrossRef]

21. Ardichvili, A.; Page, V.; Wentling, T. Motivation and barriers to participation in virtual knowledge-sharing communities of practice. J. Knowl. Manag. 2003, 7, 64-77. [CrossRef]

22. Wu, J.; Haasis, H.-D. Knowledge sharing in intermodal transport: A multi-agent based perspective. In Dynamics in Logistics; Kreowski, H., Reiter, B., Thoben, K., Eds.; Springer: Berlin, Germany, 2013; pp. $35-47$.

23. Van den Hooff, B.; de Ridder, J.A. Knowledge sharing in context: The influence of organizational commitment, communication climate and cmc use on knowledge sharing. J. Knowl. Manag. 2004, 8, 117-130. [CrossRef]

24. Cleveland, S.; Ellis, T.J. The impact of role conflict, role ambiguity, and locus of control on organizational knowledge sharing practices. In Proceedings of the Hawaii International Conference on System Sciences, Kauai, HI, USA, 5-8 January 2015; pp. 3801-3810.

25. Belkin, N.J. Anomalous states of knowledge as a basis for information retrieval. Can. J. Inform. Sci. 1980, 5, 133-143.

26. Pirolli, P.; Card, S. Information foraging. Psychol. Rev. 1999, 106, 643-675. [CrossRef]

27. Connelly, C.E.; Kelloway, E.K. Predictors of employees' perceptions of knowledge sharing cultures. Leadersh. Organ. Dev. J. 2003, 24, 294-301. [CrossRef]

28. Bock, G.-W.; Zmud, R.W.; Kim, Y.-G.; Lee, J.-N. Behavioral intention formation in knowledge sharing: Examining the roles of extrinsic motivators, social-psychological forces, and organizational climate. MIS Q. 2005, 29, 87-111.

29. Lin, H.F. Impact of organizational support on organizational intention to facilitate knowledge sharing. Knowl. Manag. Res. Pract. 2006, 4, 26-35. [CrossRef]

30. Tiwana, A. The Knowledge Management Toolkit: Orchestrating IT, Strategy, and Knowledge Platforms; Prentice Hall: Upper Saddle River, NJ, USA, 2002.

31. Fernie, S.; Green, S.D.; Weller, S.J.; Newcombe, R. Knowledge sharing: Context, confusion and controversy. Int. J. Proj. Manag. 2003, 21, 177-187. [CrossRef]

32. Lee, J.H.; Kim, Y.G. A stage model of organizational knowledge management: A latent content analysis. Expert Syst. Appl. 2001, 20, 299-311. [CrossRef]

33. Nonaka, I. A dynamic theory of organizational knowledge creation. Organ. Sci. 1994, 5, 14-37. [CrossRef]

34. Nonaka, I.; Takeuchi, H. The Knowledge-Creating Company: How Japanese Companies Create the Dynamics of Innovation; Oxford University Press: Oxford, UK, 1995.

35. Koskinen, K.U.; Aramo-Immonen, H. Remembering with the help of personal notes in a project work context. Int. J. Manag. Proj. Bus. 2008, 1, 193-205. [CrossRef]

36. Petre, M. Team coordination through externalized mental imagery. Int. J. Hum.-Comput. Stud. 2004, 61, 205-218. [CrossRef]

37. Tsoukas, H. A dialogical approach to the creation of new knowledge in organizations. Organ. Sci. 2009, 20, 941-957. [CrossRef]

38. Jonassen, D.H.; Hernandez-Serrano, J. Case-based reasoning and instructional design: Using stories to support problem solving. Educ. Technol. Res. Dev. 2002, 50, 65-77. [CrossRef] 
39. Knipfer, K.; Kump, B.; Wessel, D.; Cress, U. Reflection as a catalyst for organisational learning. Stud. Contin. Educ. 2013, 35, 30-48. [CrossRef]

40. Loo, R. Journaling: A learning tool for project management training and team-building. Proj. Manag. J. 2002, $33,61-66$.

41. Johansson, C.; Chirumalla, K.; Bertoni, M.; Isaksson, O. Capturing and sharing lessons learned across boundaries: A video-based approach. In Proceedings of the 20th European Conference on Information Systems (ECIS), Barcelona, Spain, 10-13 June 2012; p. 12.

42. De Jong, T.; Ferguson-Hessler, M.G. Types and qualities of knowledge. Educ. Psychol. 1996, 31, $105-113$. [CrossRef]

43. Cleveland, S.; Ellis, T.; Hinojosa, C. Knowledge exchange via unified communication services: A grounded theory approach. In Proceedings of the 21st Americas Conference on Information Systems, Puerto Rico, 13-15 August 2015.

44. Lopez-Nicolas, C.; Soto-Acosta, P. Analyzing ICT adoption and use effects on knowledge creation: An empirical investigation in smes. Int. J. Inform. Manag. 2010, 30, 521-528. [CrossRef]

45. Kankanhalli, A.; Tan, B.C.; Wei, K.K. Understanding seeking from electronic knowledge repositories: An empirical study. J. Am. Soc. Inform. Sci. Technol. 2005, 56, 1156-1166. [CrossRef]

46. Rojko, K.; Lesjak, D.; Vehovar, V. Information communication technology spending in (2008-) economic crisis. Ind. Manag. Data Syst. 2011, 111, 391-409. [CrossRef]

47. Hanseth, O.; Lyytinen, K. Theorizing about the design of information infrastructures: Design kernel theories and principles. Sprouts Work. Pap. Inform. Environ. Syst. Organ. 2004, 4, 207-241.

48. Java, A.; Song, X.; Finin, T.; Tseng, B. Why we twitter: Understanding microblogging usage and communities. In Proceedings of the 9th WebKDD and 1st SNA-KDD 2007 Workshop on Web Mining and Social Network Analysis, San Jose, CA, USA, 12 August 2007; pp. 56-65.

49. Malhotra, C.K.; Malhotra, A. How CEOs can leverage twitter. MIT Sloan Manag. Rev. 2016, 57, 73.

50. Yang, C.; Chang, Y.S. Assessing the effects of interactive blogging on student attitudes towards peer interaction, learning motivation, and academic achievements. J. Comput. Assist. Learn. 2012, 28, 126-135. [CrossRef]

51. Ebner, M.; Mauerer, H. Can microblogs and weblogs change traditional scientific writing? In Proceedings of the E-Learn 2008, Las Vegas, NV, USA, 17 November 2008; pp. 768-776.

52. Ebner, M.; Lienhardt, C.; Rohs, M.; Meyer, I. Microblogs in higher education-A chance to facilitate informal and process-oriented learning? Comput. Educ. 2010, 55, 92-100. [CrossRef]

53. Alavi, M.; Leidner, D.E. Knowlede management and knowledge management systems: Conceptual foundations and research issues. MIS Q. 2001, 25, 107-136. [CrossRef]

54. Zhao, D.; Rosson, M.B.; Matthews, T.; Moran, T. Microblogging's impact on collaboration awareness: A field study of microblogging within and between project teams. In Proceedings of the International Conference on Collaboration Technologies and Systems (CTS), Philadelphia, PA, USA, 23-27 May 2011; pp. 31-39.

55. Xu, Y.; Tan, C.; Yang, L. Who will you ask? An empirical study of interpersonal task information seeking. J. Am. Soc. Inform. Sci. Technol. 2006, 57, 1666-1677. [CrossRef]

56. Zhao, D.; Rosson, M.B. How might microblogs support collaborative work. In Proceedings of the Workshop on Social Networking in Organizations, San Diego, CA, USA, 9 November 2008.

57. Meyer, P.; Dibbern, J. An exploratory study about microblogging acceptance at work. In Proceedings of the 16th Americas Conference on Information Systems (AMCIS), Lima, Peru, 12-15 August 2010.

58. Davis, F.D. Perceived usefulness, perceived ease of use, and user acceptance of information technology. MIS Q. 1989, 13, 319-340. [CrossRef]

59. Hsu, C.-L.; Lin, J.C.-C. Acceptance of blog usage: The roles of technology acceptance, social influence and knowledge sharing motivation. Inform. Manag. 2008, 45, 65-74. [CrossRef]

60. Morris, M.R.; Counts, S.; Roseway, A.; Hoff, A.; Schwarz, J. Tweeting is believing? Understanding microblog credibility perceptions. In Proceedings of the ACM 2012 conference on Computer Supported Cooperative Work, Seattle, WA, USA, 11-15 February 2012; pp. 441-450.

61. Ko, D.-G.; Kirsch, L.J.; King, W.R. Antecedents of knowledge transfer from consultants to clients in enterprise system implementations. MIS Q. 2005, 29, 59-85.

62. Slaughter, S.; Kirsch, L. Transferring Evaluative Knowledge: The Case of Software Metrics; Working Paper \#2000-08; Carnegie Mellon University: Pittsburgh, PA, USA, 2000. 
63. Cabrera, E.F.; Cabrera, A. Fostering knowledge sharing through people management practices. Int. J. Hum. Resour. Manag. 2005, 16, 720-735. [CrossRef]

64. Zhao, D.; Rosson, M.B. How and why people twitter: The role that micro-blogging plays in informal communication at work. In Proceedings of the 2009 International Conference on Supporting Group Work, Sanibel Island, FL, USA, 10-13 May 2009; pp. 243-252.

65. Bass, B.M.; Riggio, R.E. Transformational Leadership; Psychology Press: Manhaw, NJ, USA, 2006.

66. Gagné, M. A model of knowledge-sharing motivation. Hum. Resour. Manag. 2009, 48, 571-589. [CrossRef]

67. Müller, J.; Stocker, A. Enterprise microblogging for advanced knowledge sharing: The references@ BT case study. J. UCS 2011, 17, 532-547.

68. Hauptmann, S.; Gerlach, L. Microblogging as a tool for networked learning in production networks. In Proceedings of the 7th International Conference on Networked Learning, Aalborg, Denmark, 3-4 May 2010; pp. 176-182.

69. Ehrlich, K.; Shami, N.S. Microblogging inside and outside the workplace. In Proceedings of the Fourth International Conference on Weblogs and Social Media, Washington, DC, USA, 23-26 May 2010; pp. 42-49.

70. Kyoon Yoo, D.; Vonderembse, M.A.; Ragu-Nathan, T. Knowledge quality: Antecedents and consequence in project teams. J. Knowl. Manag. 2011, 15, 329-343. [CrossRef]

71. Kankanhalli, A.; Lee, O.-K.D.; Lim, K.H. Knowledge reuse through electronic repositories: A study in the context of customer service support. Inform. Manag. 2011, 48, 106-113. [CrossRef]

72. André, P.; Bernstein, M.; Luther, K. Who gives a tweet? Evaluating microblog content value. In Proceedings of the ACM 2012 Conference on Computer Supported Cooperative Work, Seattle, WA, USA, 11-15 February 2012; pp. 471-474.

73. Ha, S.; Ahn, J. Why are you sharing others' tweets? The impact of argument quality and source credibility on information sharing behavior. In Proceedings of the 32th International Conference on Information Systems (ICIS 2011), Shanghai, China, 4-7 December 2011.

74. Wukich, C.; Mergel, I. Reusing social media information in government. Gov. Inform. Q. 2016, 33, 305-312. [CrossRef]

75. Cheng, H.Y. Applying Twitter to EFL Reading and Writing in a Taiwanese College Setting. Ph.D. Dissertation, Indiana State University, Terre Haute, IN, USA, 2012.

76. Cleveland, S. Using microblogging for lessons learned in information systems projects. In Proceedings of the 7th International Research Workshop on Information Technology Project Management (IRWITPM), Orlando, FL, USA, 15 December 2012.

77. Riemer, K.; Altenhofen, A.; Richter, A. What are you doing? Enterprise microblogging as context building. In Proceedings of the 19th European Conference on Information Systems, Helsinki, Finland, 9-11 June 2011.

78. Riemer, K.; Richter, A. Tweet inside: Microblogging in a corporate context. In Proceedings of the 23rd Bled eConference, Bled, Slovenia, 20-23 June 2010; pp. 1-17.

79. Panahi, S.; Watson, J.; Partridge, H. Information encountering on social media and tacit knowledge sharing. J. Inform. Sci. 2015. [CrossRef]

80. Grace, R.; Leskovich, R. Challenges in the use of social media data for the next generation analyst. Proc. SPIE 2015. [CrossRef]

81. Kywe, S.M.; Hoang, T.-A.; Lim, E.-P.; Zhu, F. On recommending hashtags in twitter networks. In Social Informatics; Springer: Berlin, Germany, 2012; pp. 337-350.

82. Chui, M.; Manyika, J.; Bughin, J.; Dobbs, R.; Roxburgh, C.; Sarrazin, H.; Sands, G.; Westergren, M. The Social Economy: Unlocking Value and Productivity Through Social Technologies; McKinsey Global Institute: London, UK, 2012.

83. Levenstein, J. Email Statistics Report, 2013-2017; The Radicati Group, Inc.: Palo Alto, CA, USA, 2013.

(C) 2016 by the author; licensee MDPI, Basel, Switzerland. This article is an open access article distributed under the terms and conditions of the Creative Commons Attribution (CC-BY) license (http://creativecommons.org/licenses/by/4.0/). 